From the Association

of Family Medicine Residency Directors

Ann Fam Med 2011;9:375. doi:10.1370/afm.1285

\section{HITTING THE GROUND RUNNING: MEDICAL STUDENT PREPAREDNESS FOR RESIDENCY TRAINING}

The fundamental task of all program directors is to graduate residents who are prepared and competent to practice the scope of family medicine "without direct supervision." There is a sense that this is becoming increasingly difficult. Even before July's anticipated duty hour changes, there is data to suggest that at least based on board scores, recent graduates are not as prepared for practice as we would like. That said, the skill sets of entering residents have been impacted by changes in medical school training.

During the March AFMRD Board of Directors meeting, the topic of medical student preparedness for residency arose for discussion. Similarly, this issue was discussed at the February AAFP Commission on Education meeting. There, program directors, residency faculty, and medical students weighed in. Some directors reported that medical students currently enter residency with less hands-on experience in everything from maternity care and procedures to placing orders and writing notes. Medical students astutely pointed out that they do not come into training with less knowledge but rather different knowledge than in prior years. Instead of performing procedures they are learning about evidence based medicine and how to navigate multiple electronic medical record systems. Furthermore, as the body of information in medicine is greater than in the past, they are ahead of prior graduates in some areas of medical knowledge.

This may seem like a matter of perception. A review of recent literature reveals, however, that this concern is not uniquely American, nor is it confined to family medicine. ${ }^{1-4}$ The transition from student to physician is not merely a graduation, but a growth spurt extraordinaire. On day one, the newly minted MD steps into the role of a practicing physician and may perform tasks never seen, nor seen modeled before.

In asking whether medical students are prepared, we reach more fundamental questions. Does a core of experience define the well-prepared medical student? What exactly do students need to facilitate the transition from student to resident? Are medical schools currently providing adequate environments for this experience and transition? How do we find out?

Looking to the current literature, it is difficult to find answers to these basic questions. There are, however, a number of innovative programs described with hopes of easing this transition. These include 4 th-year reform, mini/capstone courses, "intern boot camp," and simulation programs. ${ }^{5-9}$ One critical area appears to be the need to reinstate the role of medical students in clerkship years to allow students greater participation, ownership, and responsibility for patient care and decision making with a maximum of direct supervision.

The issue of medical student preparedness for residency is vital to the role of residency directors. Ultimately, directors need to provide medical schools with information concerning the competencies expected of first year residents so that medical schools can accommodate those needs within their curriculum, and fledgling physicians may enter residency more prepared. This may require us to work in tandem with our research colleagues to help us more clearly define the problems, as well as solutions.

Karen Hall, $M D_{i}$ Benjamin Schneider, $M D$ Stoney Abercrombie, $M D_{i}$ Joseph Gravel Jr., $M D_{i}$ Grant Hoekzema, $M D_{i}$ Stanley Kozakowski, $M D_{i}$ Michael Mazzone, $M D_{i}$ Todd Shaffer, $M D_{i}$

Martin Wieschbaus, MD

\section{References}

1. Bansal PK, Saoji VA, Gruppen LD. From a 'generalist' medical graduated to a 'specialty' resident: can an entry-level assessment facilitate the transition? Ann Acad Med Singapore. 2007;36(9):719-724.

2. Abuhusain H, Chotirmall SH, Hamid N, O'Neill SJ. Prepared for internship? Ir Med J. 2009;102(3):82-84.

3. Dare A, Fancourt N, Robinson E, Wilkinson T, Bagg W. Training the intern: the value of a pre-intern year in preparing students for practice. Med Teach. 2009;31(8):e345-e350.

4. Cave J, Goldacre M, Lambert T, Woolf K, Jones A, Dacre J. Newly qualified doctors' views about whether their medical school had trained them well: questionnaire surveys. BMC Med Educ. 2007;7:38.

5. Coates WC, Crooks K, Slavin SJ, Guiton G, Wilkerson L. Medical school curricular reform: fourth-year colleges improve access to career mentoring and overall satisfaction. Acad Med. 2008;83(8):754-760.

6. Fisher JW, Thompson BM, Garcia AD. Integrative clinical experience: an innovative program to prepare for internship. Teach Learn Med. 2007;19(3):302-307.

7. Laack TA, Newman JS, Goyal DG, Torsher LC. A 1-week simulated internship course helps prepare medical students for transition to residency. Simul Healthc. 2010;5(3):127-132.

8. Schwind CJ, Boehler ML, Markwell SJ, Williams RG, Brenner MJ. Use of simulated pages to prepare medical students for internship and improve patient safety. Acad Med. 2011;86(1):77-84.

9. Tweed MJ, Bagg W, Child S, Wilkinson T, Weller JM. How the trainee intern year can ease the transition from undergraduate education to postgraduate practice. N Z Med J. 2010;123(1318):81-91. 